Check for updates

Cite this: RSC Adv., 2020, 10, 21795

\title{
A titanium dioxide/nitrogen-doped graphene quantum dot nanocomposite to mitigate cytotoxicity: synthesis, characterisation, and cell viability evaluation
}

\author{
Pravena Ramachandran, ${ }^{a}$ Chong Yew Lee, (DD ${ }^{\mathrm{b}}$ Ruey-An Doong, (D) ${ }^{c}$ Chern Ein Oon, ${ }^{d}$ \\ Nguyen Thi Kim Thanh (D) and Hooi Ling Lee (iD) *a
}

Titanium dioxide nanoparticles $\left(\mathrm{TiO}_{2} \mathrm{NPs}\right.$ ) have attracted tremendous interest owing to their unique physicochemical properties. However, the cytotoxic effect of $\mathrm{TiO}_{2} \mathrm{NPs}$ remains an obstacle for their wide-scale applications, particularly in drug delivery systems and cancer therapies. In this study, the more biocompatible nitrogen-doped graphene quantum dots ( $N$-GQDs) were successfully incorporated onto the surface of the $\mathrm{TiO}_{2} \mathrm{NPs}$ resulting in a $\mathrm{N}-\mathrm{GQDs} / \mathrm{TiO}_{2}$ nanocomposites (NCs). The effects of the nanocomposite on the viability of the breast cancer cell line (MDA-MB-231) was evaluated. The N-GQDs and $\mathrm{N}-\mathrm{GQDs} / \mathrm{TiO}_{2} \mathrm{NCs}$ were synthesised using a one- and two-pot hydrothermal method, respectively while the $\mathrm{TiO}_{2}$ NPs were fabricated using microwave-assisted synthesis in the aqueous phase. The synthesised compounds were characterised using Fourier transform infrared (FTIR) spectroscopy, highresolution transmission electron microscopy (HRTEM), field emission scanning electron microscopy (FESEM) and UV-visible spectrophotometry. The cell viability of the MDA-MB-231 cell line was determined using a CellTiter 96® AQueous One Solution Cell Proliferation (MTS) assay. The obtained results indicated that a monodispersed solution of $N$-GQDs with particle size $4.40 \pm 1.5 \mathrm{~nm}$ emitted intense blue luminescence in aqueous media. The HRTEM images clearly showed that the $\mathrm{TiO}_{2}$ particles $(11.46 \pm 2.8 \mathrm{~nm})$ are square shaped. Meanwhile, $\mathrm{TiO}_{2}$ particles were located on the $2 \mathrm{D}$ graphene nanosheet surface in $\mathrm{N}-\mathrm{GQDs} / \mathrm{TiO}_{2} \mathrm{NCs}(9.16 \pm 2.4 \mathrm{~nm})$. N-GQDs and $\mathrm{N}-\mathrm{GQDs} / \mathrm{TiO}_{2} \mathrm{NCs}$ were not toxic to the breast cancer cells at $0.1 \mathrm{mg} \mathrm{mL}^{-1}$ and below. At higher concentrations $\left(0.5\right.$ and $\left.1 \mathrm{mg} \mathrm{mL}^{-1}\right)$, the nanocomposite was significantly less cytotoxic compared to the pristine $\mathrm{TiO}_{2}$. In conclusion, this nanocomposite with reduced cytotoxicity warrants further exploration as a new $\mathrm{TiO}_{2}$-based nanomaterial for biomedical applications, especially as an anti-cancer strategy.

Received 31st March 2020

Accepted 1st June 2020

DOI: $10.1039 / d 0 r a 02907 f$

rsc.li/rsc-advances

\section{Introduction}

With the current growth of the nanotechnology sector, extensive production of engineered NPs and their diverse application in industrial and pharmaceutical fields are rapidly expanding. Among the existing nanoparticles, $\mathrm{TiO}_{2}$ NPs have gained interest because of their physicochemical properties which make them appropriate materials in heterogeneous catalysis,

\footnotetext{
${ }^{a}$ Nanomaterials Research Group, School of Chemical Sciences, Universiti Sains Malaysia, 11800 USM, Penang, Malaysia. E-mail: hllee@usm.my

${ }^{b}$ School of Pharmaceutical Sciences, Universiti Sains Malaysia, 11800 USM, Penang, Malaysia

'Institute of Analytical and Environmental Sciences, National Tsing Hua University, Hsinchu, 30013, Taiwan

${ }^{d}$ Institute for Research in Molecular Medicine (INFORMM), Universiti Sains Malaysia, 11800 USM, Penang, Malaysia

${ }^{e} U C L$ Healthcare Biomagnetic and Nanomaterials Laboratories, 21, Albemarle Street, London, W1S $4 B S, U K$
}

cosmetic products, self-cleaning surfaces, pharmaceutical applications, water splitting and photoelectrochemical conversion. ${ }^{1}$

Titanium dioxide $\left(\mathrm{TiO}_{2}\right)$ resembles the group of transition metal oxides. $\mathrm{TiO}_{2}$ is an n-type semiconductor, has high chemical and physical stability, potent antimicrobial properties, low toxicity, low cost and excellent photocatalytic properties which are related to the electron-hole pair generation process. ${ }^{2}$ Therefore, the photoexcited electrons and holes can be utilised to liberate reactive oxygen species (ROS). ${ }^{3,4}$ The ROS produced are essential in degrading organic contaminants and germs, and for biomedical applications such as photodynamic and sonodynamic therapy in cancer treatment. ${ }^{5}$ Despite the various traits, this metal oxide has also attracted much attention as an active agent since it involves directly in photosimulation in photodynamic application, in contrast with passive nanoparticles such as silica, polyacrylamide, and gold which require conjugation with photosensitive agents. ${ }^{6,7}$ 
Although $\mathrm{TiO}_{2}$ NPs have great prospect in various fields, its application could be limited by the toxicity issue. ${ }^{8}$ Generally, $\mathrm{TiO}_{2}$ particles in bulk have been considered biologically inert, while toxicity of nanoscale particles remains unclear. ${ }^{9}$ As such, International Agency for Research on Cancer (IARC) has classified $\mathrm{TiO}_{2}$ NPs as a group 2B carcinogen. ${ }^{\mathbf{1 0}}$

One of the promising strategies to overcome this toxicity issue is via surface modification by fabricating semiconductor heterojunctions. For example, the materials can be incorporated with additional components including transition metals $(\mathrm{Cu}, \mathrm{Zn}$ and $\mathrm{Fe}),{ }^{11,12}$ noble metals $(\mathrm{Ag}, \mathrm{Pt} \text { and } \mathrm{Pd})^{13,14}$ and other semiconductors (CdS, CdSe and NiO). ${ }^{15-17}$ Most of conventional transition metals, semiconductors and noble metals are unstable or induce toxicity leading to environmental issues and impeding their benefits except Fe metal, since the excited electrons in conduction band is taken up by $\mathrm{Fe}^{3+}$. Thus, it promotes recombination of $\mathrm{e}^{-} / \mathrm{h}^{+}$pair and reduces superoxide that lower the toxicity of $\mathrm{TiO}_{2}$ NPs. ${ }^{18}$ Meanwhile, loading with noble metals such as Pt is considered to be more effective due to their anti-cancer activity, ${ }^{\mathbf{1 4}}$ but the high cost of the metal restricts their application.

Alternatively, the utilisation of nanostructure carbonaceous materials (carbon nanotube, graphene and graphene oxide) to modify $\mathrm{TiO}_{2}$ NPs has created great interest in researchers. Besides having excellent absorption capacity, efficient charge separation properties and have good biocompatibility, N-GQDs inherit unique properties of both graphene and quantum dots. ${ }^{19}$ In addition, heteroatom doping ( $\mathrm{N}$ atom) of GQDs results in high quantum yield, good stability and higher catalytic activity by tuning their electrochemical properties. ${ }^{20}$ Moreover, its large surface area-to-volume ratio with delocalised electrons increases drug loading efficiency through their $\pi-\pi$ stacking interactions which has been widely used to deliver drug molecules to cells. ${ }^{21}$ Furthermore, versatile characteristics and low toxicity of N-GQDs have resulted in wide-scale applications such as electrocatalysis, ${ }^{22}$ optoelectronic devices, ${ }^{23}$ fluorescent sensors, ${ }^{24}$ hydrogen storage, ${ }^{25}$ including tissue engineering, biosensing, molecular imaging, drug and gene delivery. ${ }^{21,26}$

Various conventional methods such as sol-gel technique, ${ }^{27}$ chemical vapour deposition, ${ }^{28}$ solvothermal ${ }^{29}$ and sonochemical method ${ }^{30}$ are applied to synthesise metal $\mathrm{TiO}_{2}$ NPs. Among these methods, hydrothermal is one of the best-performing methods to synthesise mesoporous $\mathrm{TiO}_{2}$. However, this method is generally time-consuming and cumbersome. ${ }^{31}$ Microwave heating is an alternative method to produce $\mathrm{TiO}_{2}$ in short time with less energy usage. As compared to traditional heating method, microwave heating is simultaneous, selective and rapid which leads to molecular homogeneity and thus results in greater production efficiency and uniform products with better properties. ${ }^{32}$ Although microwave-assisted synthesis efficient, very limited reports are on aqueous phase synthesis have been documented. Recent efforts on fabricating N-GQDs using electrochemical, liquid exfoliation, electron beam lithography, acid exfoliation and solvothermal cutting are not satisfactory owing to complex preparation procedure, timeconsuming and require expensive equipment. ${ }^{33}$ Hence, in this context, a facile bottom-up hydrothermal method has been considered as a good candidate to prepare N-GQDs. Similarly, $\mathrm{TiO}_{2}$ based N-GQDs nanocomposite is usually prepared via facile physical mixing of $\mathrm{TiO}_{2}$ NPs and N-GQDs followed by hydrothermal route synthesis, meanwhile in this work, a simple and easy two pot hydrothermal method was employed to synthesise this nanocomposite. ${ }^{34}$

In this study, $\mathrm{N}-\mathrm{GQDS}$ and $\mathrm{N}-\mathrm{GQDS} / \mathrm{TiO}_{2} \mathrm{NCs}$ are synthesised using hydrothermal method. Meanwhile, $\mathrm{TiO}_{2}$ NPs are fabricated using microwave-assisted hydrothermal method in aqueous phase. Their potential cytotoxicity was studied using MDA-MB-231 cells as a model cancer cell line.

\section{Experimental}

\subsection{Materials}

Citric acid-1-hydrate (Bendosen, Laboratory Chemicals), ethylenediamine (QREC, Grade AR, (Asia) Sdn. Bhd, Malaysia), titanium(Iv) tetraisopropoxide, TTIP $\geq 97 \%$ purity (Sigma-Aldrich, Co., USA), hydrochloric acid (HCl, 37\%, QREC, Grade AR, (Asia) Sdn. Bhd, Malaysia), purchased pure anatase, $\geq 99 \%$ (SigmaAldrich, Co., USA). Dulbecco's modified eagle's medium (DMEM) and penicillin-streptomycin mixed solution (Nacalai Tesque, Japan), fetal bovine serum (FBS) (TICO Europe, Netherlands), phosphate buffered saline (Sigma-Aldrich, Co., Germany), Trypsin-EDTA (GibcoTM, Life Technologies, Canada) and CellTiter 96® AQueous One Solution Cell Proliferation Assay (MTS, Promega, USA) were purchased. All reagents were used as purchased and without further purification.

\subsection{Synthesis of N-GQDs}

The N-GQDs were synthesised via hydrothermal method with citric acid (CA) and ethylenediamine (EDA) used as carbon and nitrogen precursors, respectively. The synthesis was carried out based on the previous study ${ }^{35}$ with some modifications. 1 mol of $\mathrm{CA}$ and $1 \mathrm{~mol}$ of EDA were dissolved in $5 \mathrm{~mL}$ of ultrapure water and stirred to form a clear solution. The solution was then transferred into a $20 \mathrm{~mL}$ Teflon-lined stainless-steel autoclave followed by hydrothermal treatment at $180{ }^{\circ} \mathrm{C}$ for $4 \mathrm{~h}$. The asreceived black-brown transparent solution was centrifuged at $5000 \mathrm{rpm}$ for $5 \mathrm{~min}$. Then, the final product was dialyzed in 1 $\mathrm{kDa}$ dialysis bag for $24 \mathrm{~h}$ to remove the unreacted chemicals and preserved in dark at $4{ }^{\circ} \mathrm{C}$ for further use. The stability of the synthesised N-GQDs were studied for the period of two months using UV-vis spectroscopy. The absorbance of the similar concentration sample was taken every 2 weeks once.

\subsection{Synthesis of $\mathrm{TiO}_{2}$ NPs}

The $\mathrm{TiO}_{2}$ NPs were fabricated by adding $2 \mathrm{~mL}$ TTIP in $50 \mathrm{~mL}$ of distilled water with continuous stirring to form a homogeneous solution. The $\mathrm{pH}$ of the solution was adjusted to $\mathrm{pH} 1.3$ by slowly adding $37 \%$ hydrochloric acid with constant stirring for $30 \mathrm{~min}$ and then transferred to a $100 \mathrm{~mL}$ sealed vessel made of high-purity TFM (modified Teflon) placed in a commercial microwave digestion system (Multiwave 3000 Antor Paar, Austria). This equipment was programmed at $600 \mathrm{~W}$ of power for $20 \mathrm{~min}$. The resulting precipitate was centrifuged at $8500 \mathrm{rpm}$ 
for $10 \mathrm{~min}$, followed by several cycles of washing with distilled water and finally dried in an oven at $50{ }^{\circ} \mathrm{C}$. The dried asobtained powder was further calcined in air at $500{ }^{\circ} \mathrm{C}$ for $2 \mathrm{~h}$ to obtain $\mathrm{TiO}_{2}$ NPs.

\subsection{Synthesis of N-GQDs/ $\mathrm{TiO}_{2} \mathrm{NCs}$}

The N-GQDs/TiO 2 NCs were synthesised via two-pot hydrothermal technique. Initially, $3 \mathrm{~mL}$ of TTIP was added into $50 \mathrm{~mL}$ distilled water under magnetic stirring for $30 \mathrm{~min}$. The solution was then treated by a hydrothermal method in Teflon-lined stainless-steel autoclave $(100 \mathrm{~mL})$ at $160{ }^{\circ} \mathrm{C}$ for $24 \mathrm{~h}$. After cooling to room temperature, the obtained precipitates were carefully washed with distilled water and centrifuged at a rotation speed of $8500 \mathrm{rpm}$ for $10 \mathrm{~min}$. Then $50 \mathrm{~mL}$ of distilled water was added to the sol under magnetic stirring. The entire process was followed using the same procedure used for the synthesis of N-GQDs. Both citric acid and ethylenediamine were added simultaneously to the solution. The solution was further magnetically stirred for $30 \mathrm{~min}$. Following this, the reaction was carried out by heating in a closed hydrothermal system at $180^{\circ} \mathrm{C}$ for $4 \mathrm{~h}$. The resulting composites were recovered by centrifugation (15 min, $5000 \mathrm{rpm}$ ), washed with distilled water and dried under vacuum oven at $60{ }^{\circ} \mathrm{C}$ overnight.

\subsection{Characterisations}

Fourier Transform Infrared (FTIR) spectrum of the assynthesized sample was recorded by the $\mathrm{KBr}$ method on PerkinElmer System 2000 FT-IR in the range of 500-4000 $\mathrm{cm}^{-1}$, ATR method on PerkinElmer FT-NIR Spectrometer Frontier. The morphology and size distribution of the product were determined using field emission scanning electron microscope (FESEM) (Leo Supra 50 VP Field Emission SEM) and HRTEM (FEI Titan Krios FEG at $300 \mathrm{kV}$ ). Further optical characterisation was carried out via UV-visible spectroscopy (PerkinElmer Lambda 35 ) at $200-400 \mathrm{~nm}$ of wavelength range to determine the light absorption of synthesised nanomaterials. Dynamic light scattering (DLS) measurements acquired using Malvern Zetasizer Nano ZS to measure hydrodynamic size and zeta potential of the products in cell culture medium with different percentage of FBS.

\subsection{Cell culture}

Human breast epithelial cancer cell line (MDA-MB-231) was obtained from Dr Chern Ein Oon (INFORMM, USM). Cells were cultured in DMEM medium supplemented with 10\% FBS and $1 \%$ penicillin-streptomycin, incubated at $37{ }^{\circ} \mathrm{C}$ with $5 \% \mathrm{CO}_{2}$.

\subsection{Nanoparticle preparation and exposure to cells}

The N-GQDs, autoclave $\mathrm{TiO}_{2}$ NPs and N-GQDs/TiO ${ }_{2}$ NCs were individually suspended in DMEM medium at a concentration of $1.0 \mathrm{mg} \mathrm{mL}{ }^{-1}$. Both $\mathrm{TiO}_{2}$ NPs and N-GQDs/TiO ${ }_{2}$ NCs were dispersed by sonication for 15 min directly prior to dilution to ensure an even distribution of the nanoparticles without agglomeration. The resulting solutions of $\mathrm{TiO}_{2}$ NPs, N-GQDs/
$\mathrm{TiO}_{2}$ NCs and N-GQDs were diluted to different concentrations $\left(0.01,0.05,0.1\right.$, and $\left.0.5 \mathrm{mg} \mathrm{mL}^{-1}\right)$ before exposure to cells.

\subsection{Cytotoxicity assay}

Cytotoxicity of the synthesised products were assessed using MTS assay following the manufacturer's protocol. Briefly, the cells in 96-well plates (10 000 cells per well) were treated with medium containing various doses of N-GQDs, $\mathrm{TiO}_{2}$ NPs and NGQDs $/ \mathrm{TiO}_{2} \mathrm{NCs}$ and incubated for $48 \mathrm{~h}$. After the exposure time completed, MTS solution was added and incubated for $4 \mathrm{~h}$. Then, the plates were placed on a Multiskan Go UV microplate reader (ThermoFisher Scientific, US) and the absorbance of the solution were read $490 \mathrm{~nm}$. The cell viability was calculated according to the following eqn (1):

$$
\begin{gathered}
\text { Percentage of viable cells }(\%) \\
=\frac{\text { absorbance }(\text { treated })-\text { absorbance }(\text { blank })}{\text { absorbance }(\text { untreated })-\text { absorbance (blank) }} \times 100 \%
\end{gathered}
$$

\subsection{Statistical analysis}

Data are expressed as the mean \pm standard deviation (SD). The statistically significant differences of cell viability $(p<0.05)$ were analysed using ANOVA by GraphPad Prism 5.0 software, California.

\section{Results and discussion}

\subsection{Fourier-transform infrared spectroscopy (FTIR)}

The overlay FTIR spectra of N-GQDs, pristine $\mathrm{TiO}_{2} \mathrm{NPs}, \mathrm{N}-$ GQDs $/ \mathrm{TiO}_{2}$ NCs and pure anatase was employed to exhibit characteristics changes in the functional groups and different types chemical bonds in the synthesised nanomaterials, as shown in Fig. 1. As for N-GQDs, a broad absorption band around $3353 \mathrm{~cm}^{-1}$ is due to the stretching vibration of the $\mathrm{O}-\mathrm{H}$. The stretching vibration peaks of $\mathrm{C}-\mathrm{H}$ was at $2943 \mathrm{~cm}^{-1}$ and a vibrational absorption peak found at $1648 \mathrm{~cm}^{-1}$ is corresponded to the $\mathrm{C}=\mathrm{O}$ in the carboxyl group, while the peak at $1531 \mathrm{~cm}^{-1}$ and $1220 \mathrm{~cm}^{-1}$ belongs to the bending vibrations of $\mathrm{C}=\mathrm{C}$ and $\mathrm{C}-\mathrm{O}$, respectively. ${ }^{34}$ The two peaks at 3103 and $1381 \mathrm{~cm}^{-1}$ can be ascribed to $\mathrm{N}-\mathrm{H}$ bending vibration and $\mathrm{C}-\mathrm{N}$ in-plane bending vibration, respectively. The spectrum exhibits successful anchoring of $\mathrm{N}$-functionalization in the lattice of GQDs. ${ }^{36}$

Besides, the FT-IR spectra of pristine $\mathrm{TiO}_{2} \mathrm{NPs}, \mathrm{N}-\mathrm{GQDS} / \mathrm{TiO}_{2}$ NCs and pure anatase showed that major broad absorption band between 3300 to $3400 \mathrm{~cm}^{-1}$ and weak vibrational band around $1630 \mathrm{~cm}^{-1}$ ascribed to $\mathrm{O}-\mathrm{H}$ stretching and bending of $\mathrm{H}_{2} \mathrm{O}$ molecules, indicating the absorption of water molecules in the samples. The absorbance peaks at 591, 627 and $687 \mathrm{~cm}^{-1}$ correspond to Ti-O-Ti vibrations of pristine $\mathrm{TiO}_{2}$ NPs, N-GQDs/ $\mathrm{TiO}_{2}$ NCs and pure anatase $\mathrm{TiO}_{2} \mathrm{NPs}$, respectively. ${ }^{37}$ In the case of N-GQDs/TiO ${ }_{2} \mathrm{NCs}$, the characteristic vibration at $627 \mathrm{~cm}^{-1}$ becomes broader compared with pristine $\mathrm{TiO}_{2}$ NPs and pure anatase. This could be attributed to the combination of Ti-O-Ti 


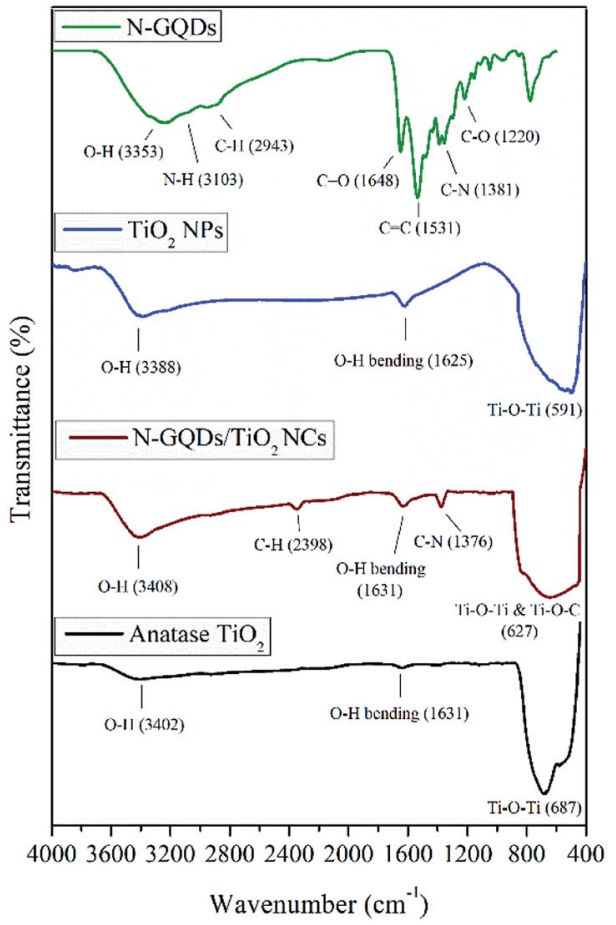

Fig. 1 Overlay of FT-IR spectra for N-GQDs, $\mathrm{TiO}_{2} \mathrm{NPs}, \mathrm{N}-\mathrm{GQDs} / \mathrm{TiO}_{2}$ $\mathrm{NCs}$ and anatase $\mathrm{TiO}_{2}$.

and Ti-O-C vibrations. ${ }^{38}$ The bond breaking of -OH group in TTIP and the $\mathrm{C}-\mathrm{O}$ group in N-GQDs during the hydrothermal reaction has resulted in the bond formation of Ti-O-C. ${ }^{39}$ Besides, there are stretching vibration peaks of $\mathrm{C}-\mathrm{H}$ at $2398 \mathrm{~cm}^{-1}$ and $\mathrm{C}-\mathrm{N}$ vibrations of amine group at $1376 \mathrm{~cm}^{-1}$ for $\mathrm{N}-\mathrm{GQDS} / \mathrm{TiO}_{2} \mathrm{NCs}$, which confirms the successful incorporation of N-GQDs with $\mathrm{TiO}_{2}{ }^{40}$

\subsection{UV-visible (UV-vis) spectroscopy}

The UV-vis absorption spectrum of N-GQDs, pristine $\mathrm{TiO}_{2} \mathrm{NPs}$, $\mathrm{N}-\mathrm{GQDS} / \mathrm{TiO}_{2} \mathrm{NCs}$ are is shown in Fig. 2. From the UV-vis

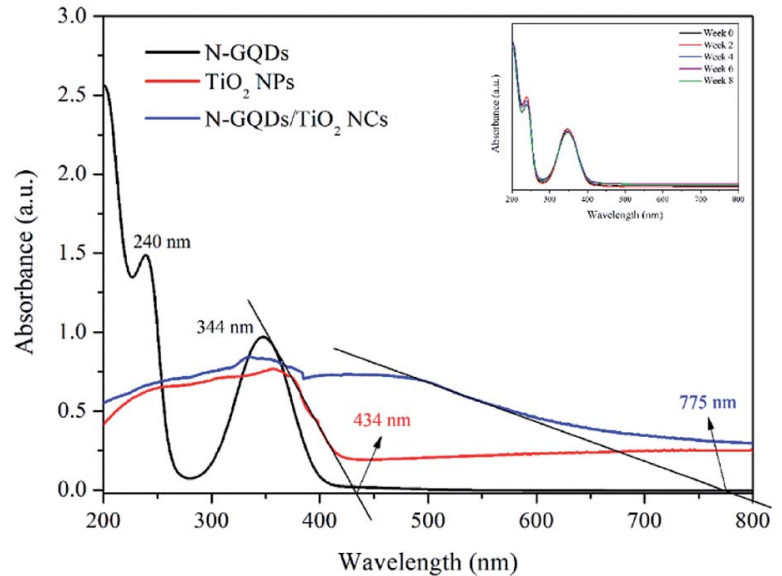

Fig. 2 Overlay of UV-vis spectra for N-GQDs, $\mathrm{TiO}_{2} \mathrm{NPS}$ and N-GQDs/ $\mathrm{TiO}_{2} \mathrm{NCs}$ spectrum of N-GQDs, two typical peaks at $240 \mathrm{~nm}$ and $344 \mathrm{~nm}$ were observed. The peak at $240 \mathrm{~nm}$ is assigned to the $\pi-\pi *$ transition of the aromatic $\mathrm{sp}^{2}$ domains, resulting in almost no photoluminescence. Meanwhile, peak at $344 \mathrm{~nm}$ corresponds to $\mathrm{n}-\pi^{*}$ transition of $\mathrm{C}=\mathrm{O}$ and $\mathrm{C}-\mathrm{N}$ in $\mathrm{N}$ substituted aromatic heterocycles, leading to strong photoluminescence emission. ${ }^{24}$ Moreover, based on inset of Fig. 2, N-GQDs exhibited excellent stability for the period of two months as the differences in the absorbance was insignificant and consistent with concentration of $0.0348 \mathrm{~g} \mathrm{~mL}^{-1}$. Besides, as shown in Fig. 2, absorption edge of pristine $\mathrm{TiO}_{2} \mathrm{NPs}$ is $434 \mathrm{~nm}$, which indicates the visible region. However, compared with those of the pristine $\mathrm{TiO}_{2}$ NPs, the absorption edge thresholds of the N-GQDs/ $/ \mathrm{TiO}_{2} \mathrm{NCs}$ are distinctly redshifted towards the near infrared (NIR) region $(775 \mathrm{~nm})$. The NIR light absorption of $\mathrm{TiO}_{2}$ NPs has been effectively enhanced by the surface modification with N-GQDs.

\subsection{Size, structure and morphology analysis}

3.3.1 High-resolution transmission electron microscope (HRTEM). The morphology and structure of the N-GQDs were confirmed by HRTEM. The HRTEM image reveals the presence of lattice fringes which correspond to the high crystalline quality of N-GQDs. From low-magnification HRTEM image (Fig. 3a), it can be seen that the N-GQDs consists of 2-D sheets. Based on Fig. 3b, spherical quantum dots are observed which distributed reasonably uniform in size with the diameter $4.40 \pm$ $1.5 \mathrm{~nm}$ without apparent agglomeration. The highmagnification images disclosed the crystalline nature of the quantum dots with prominent lattice fringes of $0.346 \mathrm{~nm}$ (Fig. 3c), $0.246 \mathrm{~nm}$ (Fig. 3d), and $0.216 \mathrm{~nm}$ (Fig. 3e), that indicates the basal plane spacing (002), in-plane lattice constant $(d$

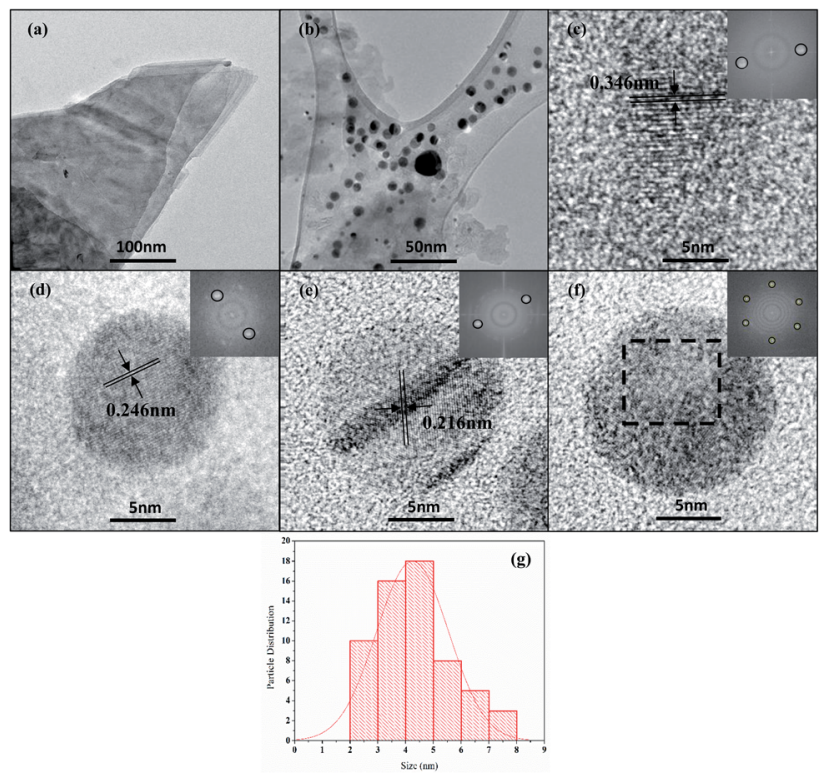

Fig. 3 (a-f) HRTEM images of N-GQDs. The insets show FFT image corresponding to the selected area, (g) particle-size distribution of $\mathrm{N}$ GQDs. 
$=0.246)$ and in-plane lattice spacing (100) of graphite, respectively. ${ }^{41}$ These lattice parameters were calculated from the Fast Fourier Transform (FFT) image of selected area, as shown in inset of Fig. 3(c, d and e), respectively. It is worth to take note that the obtained basal plane spacing $(0.346 \mathrm{~nm})$ is slightly higher as compared with bulk graphite $(0.336 \mathrm{~nm}) .{ }^{42}$ This is mainly due the presence of nitrogen doping atoms that enlarged the basal plane distance of N-GQDs. Besides, hexagonal structure of the dots can be observed from the selected area of FFT image (inset of Fig. 3f), further justifies the graphene structure.

HRTEM images of $\mathrm{TiO}_{2}$ NPs (Fig. $4 \mathrm{a}$ and b) exhibited that particles irregular square-shaped with an average particle size of $11.46 \pm 2.8 \mathrm{~nm}$ (inset of Fig. 4a). The interplanar $d$-spacings calculated from the lattice fringes correspond to the 0.351 , $0.233,0.185$, and $0.171 \mathrm{~nm}$ plane of anatase $\mathrm{TiO}_{2}$, as depicted in Fig. $4 \mathrm{c}-\mathrm{e}$. The rings in the SAED pattern (Fig. 4f) shows the typical diffuse polycrystalline pattern of anatase phase of $\mathrm{TiO}_{2}$ with the main planes identifies in (101), (004), (105) and (200) where the first ring showed well-defined concentric circle and followed by others with similar intensity. ${ }^{43}$

After the incorporation of N-GQDs in $\mathrm{TiO}_{2}$, a brown coloured powder was obtained and the corresponding HRTEM images as shown in Fig. 5. The HRTEM image (Fig. 5a and b) clearly showed that $\mathrm{TiO}_{2}$ particles were located on the $2 \mathrm{D}$ graphene nanosheets surface in a considerably uniform distribution, despite the dark area indicates that some $\mathrm{TiO}_{2}$ NPs were agglomerated on the graphene surface ${ }^{44}$ There were indistinct changes observed in the morphology of $\mathrm{TiO}_{2}$ in the N-GQDs/ $\mathrm{TiO}_{2} \mathrm{NCs}(9.16 \pm 2.4 \mathrm{~nm})$ with agglomeration as compared to that of synthesised $\mathrm{TiO}_{2}$ NPs. The lattice spacing of $0.351 \mathrm{~nm}$ (Fig. 5c) corresponds to the interplanar separation of (101) plane of $\mathrm{TiO}_{2}$, while the lattice parameter of $0.245 \mathrm{~nm}$ (Fig. 5d) is consistent with the in-plane lattice constant of graphene. ${ }^{41,43}$

3.3.2 Field emission scanning electron microscope (FESEM). FESEM was employed to study the surface morphology of synthesised $\mathrm{TiO}_{2}$ NPs and N-GQDs/TiO ${ }_{2} \mathrm{NCs}$. Fig. 6 shows the FESEM images of nanoparticles and

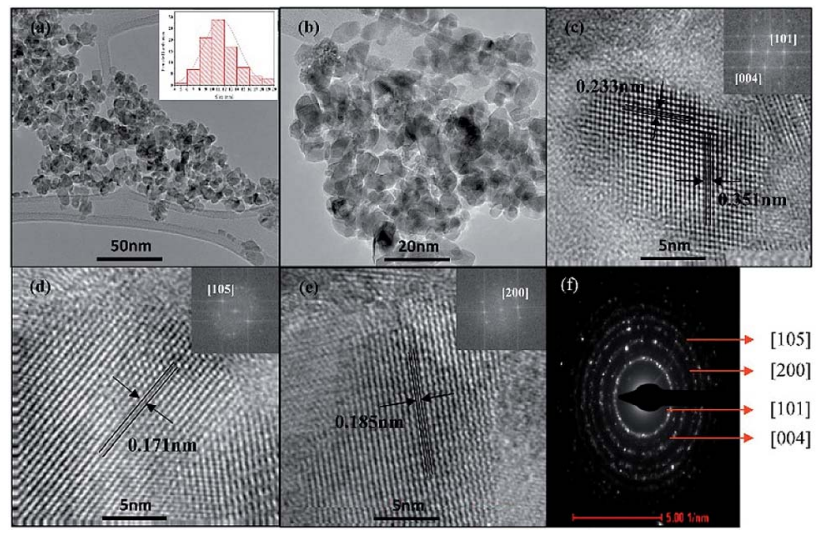

Fig. 4 (a-e) HRTEM images (f) SAED pattern. The insets show FFT image corresponding to the selected area and particle-size distribution of $\mathrm{TiO}_{2} \mathrm{NPs}$.

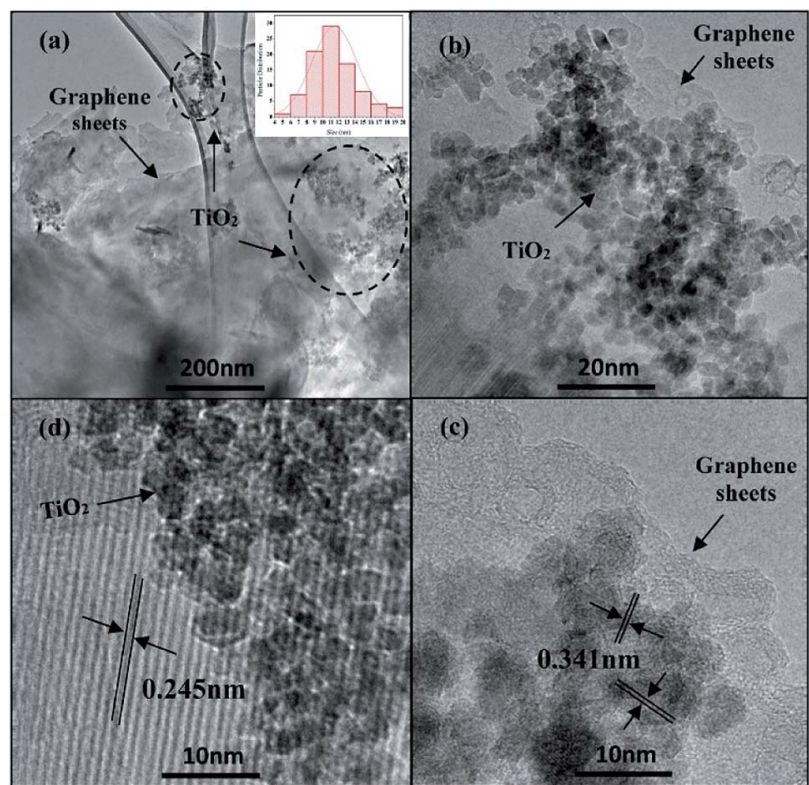

Fig. 5 (a-d) HRTEM images. The insets show particle-size distribution of $\mathrm{N}-\mathrm{GQDs} / \mathrm{TiO}_{2} \mathrm{NCs}$.

nanocomposite obtained at higher magnification. It can be observed both the $\mathrm{TiO}_{2}$ NPs were grown with agglomerated spherical morphology due to the higher surface area while $-\mathrm{COOH}$ group on the surface of N-GQDs helps to bind $\mathrm{TiO}_{2} \mathrm{NPs}$ onto N-GQDs and thus results in less agglomeration. As for $\mathrm{N}$ $\mathrm{GQDs} / \mathrm{TiO}_{2} \mathrm{NCs}$, the presence of graphene was not observed wherein the $\mathrm{TiO}_{2}$ NPs could be seen clearly. This might be due to the higher concentration of $\mathrm{TiO}_{2}$ in the nanocomposite and thus the spherical shaped agglomerates completely cover the graphene sheets. ${ }^{44}$
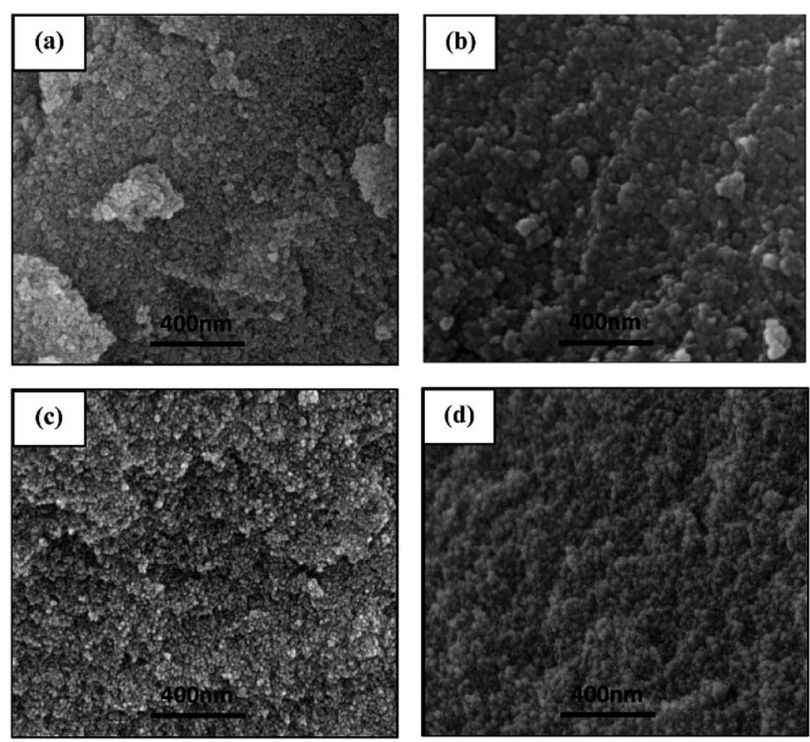

Fig. 6 FESEM images of $\left(a \&\right.$ b) $\mathrm{TiO}_{2} \mathrm{NPs}$ and (c \& d) N-GQDs/TiO 2 NCs. 


\subsection{Possible formation mechanism of N-GQDs}

The N-GQDs were synthesised using bottom-up approach which contains ionisation, condensation, polymerisation and carbonisation (graphitisation) as shown in Fig. $7 .{ }^{45}$ In this reaction, CA acts as a carbon source while EDA acts as both nitrogen source and catalyst. The reaction was carried out by first ionising the precursors in an aqueous media followed by condensation of CA and EDA to form polymer-like quantum dots. As the reaction temperature evolved from low to high, polymerisation changed into N-doped carbogenic carbon dots, and followed the graphitisation to form N-GQDs. The condensation reaction led to the formation of $\mathrm{N}$ atoms bonded with $\mathrm{C}$ in five membered-ring structures, referred to as pyrrolic N. With increasing reaction time, pyrrolic $\mathrm{N}$ is gradually transformed into graphitic and pyridinic $\mathrm{N}$. Pyridinic $\mathrm{N}$ originates from the $\mathrm{N}$ atoms that are bonded with $\mathrm{C}$ in six membered-ring while graphitic $\mathrm{N}$ indicates that $\mathrm{N}$ atoms bonded with 3 neighbour $\mathrm{C}$ atoms. $^{4}$

\subsection{Possible formation mechanism of $\mathrm{TiO}_{2} \mathrm{NPs}$}

Generally, there are two stages in the formation of nanocrystals: nucleation and growth (Fig. 8). As for microwave assisted synthesis, the reaction starts with the heating of mixture to the reaction temperature for the specified duration. This assist in the formation of abundant crystal nuclei. As the nucleation process begins, the system developed into growth stage immediately, which leads to the rapid growth of existing clusters, no additional nuclei are formed. Then, the clusters are assembled into aggregated nanocrystalline. ${ }^{46}$ The rapid heating rate of microwave-assisted synthesis greatly shorten the overall nucleation and growth processes. In the case of $\mathrm{TiO}_{2} \mathrm{NPs}$, titanium isopropoxide underwent the hydrolysis and condensation processes which occurs upon microwave irradiation. Initially, titanium isopropoxide undergone hydrolysis process in an aqueous media and titanium hydroxides $\left(\mathrm{Ti}(\mathrm{OH})_{4}\right)$ formed as an intermediate (eqn (2)). Usually, $\mathrm{Ti}(\mathrm{OH})_{4}$ is unstable and thus, condensation process of $\mathrm{Ti}(\mathrm{OH})_{4}$ occurred and formed amorphous hydrous oxide precipitates $\left(\mathrm{TiO}_{2} \cdot x \mathrm{H}_{2} \mathrm{O}\right)$ as stated in eqn (3). The $\mathrm{TiO}_{2} \cdot x \mathrm{H}_{2} \mathrm{O}$ precipitates were then calcined at $500{ }^{\circ} \mathrm{C}$ (eqn (4)). During the calcination process, water molecules were removed and anatase crystalline $\mathrm{TiO}_{2}$ NPs formed. ${ }^{47,48}$ The interaction between microwave power and solvent affects the growth of the particles after the nucleation of initial particles. This is primarily due to the dielectric properties of the solvent which ensure efficient heating and ability of the solvent to convert electromagnetic energy into heat under the microwave field. ${ }^{49}$ This heating characteristic is determined by dissipation factor (loss tangent, $\tan \delta$ ). Water has moderate $(\tan \delta=0.157)$

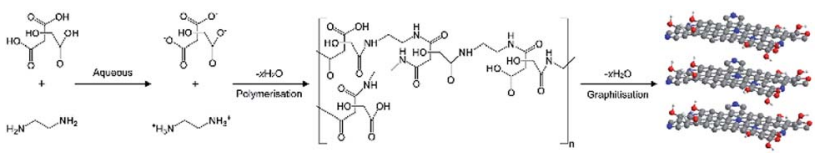

Fig. 7 Reaction mechanism of N-GQDs using citric acid and ethylenediamine.

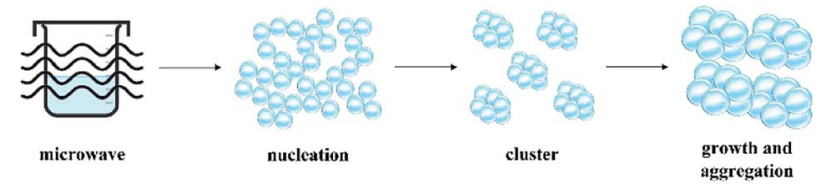

Fig. 8 Schematic illustration of the $\mathrm{TiO}_{2}$ aggregates formation process.

microwave absorbing capacity. ${ }^{50}$ Thus, microwave power interacts with water to form spherical or square-shaped mesoporous $\mathrm{TiO}_{2}$ NPs aggregates. The homogenous and rapid dielectric heating of microwave results in high degree of crystallisation of the nanoparticles.

Hydrolysis:

$\mathrm{Ti}\left(\mathrm{OCH}\left(\mathrm{CH}_{3}\right)_{2}\right)_{4}+4 \mathrm{H}_{2} \mathrm{O} \rightarrow \mathrm{Ti}(\mathrm{OH})_{4}+4\left(\mathrm{CH}_{2}\right)_{2} \mathrm{CHOH}$

Condensation:

$$
\mathrm{Ti}(\mathrm{OH})_{4} \rightarrow \mathrm{TiO}_{2} \cdot x \mathrm{H}_{2} \mathrm{O}+(2-x) \mathrm{H}_{2} \mathrm{O}
$$

Crystallisation via calcination:

$$
\mathrm{TiO}_{2} \cdot x \mathrm{H}_{2} \mathrm{O} \rightarrow \mathrm{TiO}_{2} \text { (anatase) }
$$

\subsection{Possible formation mechanism of $\mathrm{Ti}-\mathrm{O}-\mathrm{C}$ bond of $\mathrm{N}$ - GQDs/ $/ \mathrm{TiO}_{2}$ NCs}

In the formation of $\mathrm{Ti}-\mathrm{O}-\mathrm{C}$ bonds of $\mathrm{N}-\mathrm{GQDS} / \mathrm{TiO}_{2} \mathrm{NCs}$, the residual carboxylic acid functional group of N-GQDs will bind with surface hydroxyl group of $\mathrm{TiO}_{2}$ NPs during the hydrothermal process. ${ }^{51}$ The oxygen and $\mathrm{Ti}$ atoms of $\mathrm{TiO}_{2}$ surface were incompletely coordinated and hence, they have partial charge on the surface. Thus, it will attract and bind (chemisorbed) with water molecules in the aqueous solution and moisture in the air. The water molecules then dissociate, leaving a hydroxyl group bound to the surface metal ions known as terminal $\mathrm{OH}$ (eqn (5)). Similarly, the electronegative oxygen atom hydrogen bonded to the hydrogen atom of water to form bridge $\mathrm{OH}$ (eqn (6)). ${ }^{52}$ Upon the addition of N-GQDs precursors, the surface hydroxyl groups of $\mathrm{TiO}_{2}$ will interact with $-\mathrm{COOH}$ group on $\mathrm{N}$ GQDs and led to the formation of Ti-O-C bonds and release water molecules as shown in Fig. 9.

$$
\begin{aligned}
& \equiv \mathrm{Ti}^{+}+\mathrm{H}_{2} \mathrm{O} \rightarrow \equiv \mathrm{TiOH}+\mathrm{H}^{+} \\
& \equiv \mathrm{O}^{-}+\mathrm{H}_{2} \mathrm{O} \rightarrow \equiv \mathrm{OH}+\mathrm{OH}^{-}
\end{aligned}
$$

\subsection{Characterisation of $\mathrm{N}-\mathrm{GQDs}, \mathrm{TiO}_{2} \mathrm{NPs}$ and $\mathrm{N}-\mathrm{GQDS} / \mathrm{TiO}_{2}$ NCs in cell culture treatment}

Hydrodynamic size and zeta potential of NPs and NCs in deionized water (DI water) and culture medium was determined to understand the distribution of nanomaterial cell culture 

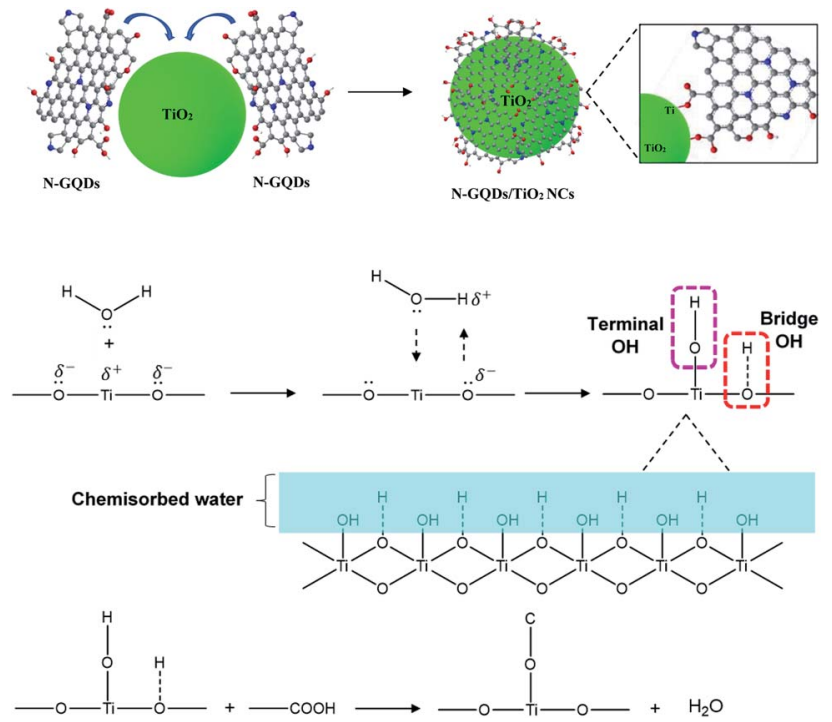

Fig. 9 Chemical synthesis process of $\mathrm{N}-\mathrm{GQDs} / \mathrm{TiO}_{2} \mathrm{NCs}$.

environment and their interaction with biological substrates. Based on Table 1, dispersing these nanomaterials in DMEM without any dispersing agent resulted in slightly higher hydrodynamic size as compared to DI water. This is probably due to high ionic strengths in cell culture medium causes van der Waals forces to dominate whereby leading to bind of particles together. ${ }^{53}$ Agglomerated particles often have higher toxicity than well dispersed particles, thus it is not recommended to investigate biological effects of agglomerated NPs. ${ }^{54}$ To improve the dispersion of these nanomaterials, FBS as a dispersing agent were employed to medium in different concentration. Upon the addition of FBS, decrease in hydrodynamic size of particles were observed for all the synthesised products. This is due to the formation of a protein corona around the particles following the rapid binding of the serum in the medium to the NPs. ${ }^{55}$ This protein corona provides steric hindrance and electrostatic repulsion between particles, thus, resulted in better dispersion. ${ }^{56,57}$ Meanwhile, there is a decrease in the hydrodynamic size of particles as the concentration decreases. This effect arises due to the electrical double-layer surrounding charged particles in the medium. As the concentration decreases, the counterion clouds that charge-compensate the charged surface of nanoparticles extend the double-layer interaction to long-range interaction. Thus, electrostatic repulsion dominates to form stable nanoparticle suspension as the van der Waals attraction is relatively weak at long-range interaction. ${ }^{57}$ Consistent with these results, the measured zeta potential value for all the synthesised NPs except N-GQDs in DI water indicated positive surface charge while negative surface charge of particles was observed in complete culture medium. The difference the surface charge could be attributed to the formation of negatively charged protein corona on the surface of these synthesised nanomaterials..$^{12}$ Meanwhile, the highly water-soluble N-GQDs has negative surface charge in both DI water and complete culture medium, which indicated good stability and anionic in nature. When comparing NPs in medium containing $5 \%$ and $1 \%$ FBS, insignificant difference in the hydrodynamic size and zeta potential value were observed. Thus, in this study, 1\% FBS stabilised medium is used to achieve highly dispersed NPs suspension, which is suitable for cellular penetration based on literature.

\subsection{In vitro cytotoxicity assessment of $\mathrm{N}-\mathrm{GQDs}, \mathrm{TiO}_{2} \mathrm{NPs}$ and $\mathrm{N}-\mathrm{GQDS} / \mathrm{TiO}_{2}$ NCs using the MDA-MB-231 breast cancer cell line}

The in vitro toxicity assay was assessed using MDA-MB-231 cells at different concentration of N-GQDs, $\mathrm{TiO}_{2}$ NPs and N-GQD/ $\mathrm{TiO}_{2}$ NCs $\left(0.01,0.05,0.1,0.5\right.$ and $\left.1.0 \mathrm{mg} \mathrm{mL}^{-1}\right)$ for $48 \mathrm{~h}$. Based on Fig. 10a, after $48 \mathrm{~h}$ exposure of N-GQDs, the viability decreases slightly, resulting in $83 \%$ viable cells at $0.5 \mathrm{mg} \mathrm{mL}^{-1}$ and further decreased to $78 \%$ at $1.0 \mathrm{mg} \mathrm{mL}^{-1}$. There was no growth inhibitory effect observed at lower concentrations (0.05$0.1 \mathrm{mg} \mathrm{mL}{ }^{-1}$ ) after $48 \mathrm{~h}$ post treatment. The obtained results corroborate with existing literature which claimed that doping GQDs with heteroatoms such as nitrogen and boron allow higher cell viability because it is biologically safe. Even though there is still no direct comparative toxicity study on GQDs and N-GQDs, generally GQDs demonstrated cell viability above $80 \%$ at a much higher administration dose of $200 \mu \mathrm{g} \mathrm{mL} \mathrm{mL}^{-1.58,59}$ Meanwhile, HeLa cells was demonstrated to be close to $95 \%$ viable even at higher concentration of $2.0 \mathrm{mg} \mathrm{mL}^{-1}$ of boron doped GQDs, suggesting that toxicity not higher than GQDs. ${ }^{59}$ Furthermore, the study on cytotoxicity of N-GQDs and graphene oxide (GO) for red blood cells has denoted N-GQDs has lower toxicity than GO. GO induce haemolysis at concentration above $50 \mu \mathrm{g} \mathrm{mL} \mathrm{m}^{-1}$, in contrast, N-GQDs did not result in any haemolysis even the concentration of N-GQDs was as high as $200 \mu \mathrm{g}$ $\mathrm{mL}^{-1} .^{60}$ Generally, N-GQDs are primarily internalised through cell endocytosis. They have been reported to enter cell membrane by diffusion to enter the nucleus, rendering direct contact with both the genetic materials and proteins in the cell. ${ }^{61}$ At higher concentration of N-GQDs, these interactions could distort the morphology of the cytoplasm and nucleus which may alter gene expression, particularly those related to cell death. These results clearly indicated N-GQDs exhibit less toxicity and excellent biocompatibility at lower concentration, and thus it can be utilised in biomedical applications.

As shown in Fig. 10b, the cytotoxicity effect was significantly higher in the MDA-MB-231 cells cultured $48 \mathrm{~h}$ post treatment. As compared to control group, cells cultured in medium containing 0.5 and $1.0 \mathrm{mg} \mathrm{mL} \mathrm{mL}^{-1} \mathrm{TiO}_{2} \mathrm{NPs}$ showed a 28 and $33 \%$ decrease in viability respectively following $48 \mathrm{~h}$ exposure. As for the lower concentrations of nanoparticles $\left(0.05-0.1 \mathrm{mg} \mathrm{mL}^{-1}\right)$, the differences in cell viability were non-significant when compared to higher concentrations $\left(0.5\right.$ and $1.0 \mathrm{mg} \mathrm{mL}^{-1}$ ). These observations were in good agreement with other reports denoting that pure $\mathrm{TiO}_{2}$ NPs induce low toxicity in different types of human cells. ${ }^{9,62,63}$ Specific characteristics of nanoparticles, for example size, crystallinity, composition are regarded as important parameters in determining the toxicity. ${ }^{13}$ As the size of the particles approaches nanoscale, the surface area and reactivity increase dramatically which lead to adverse 

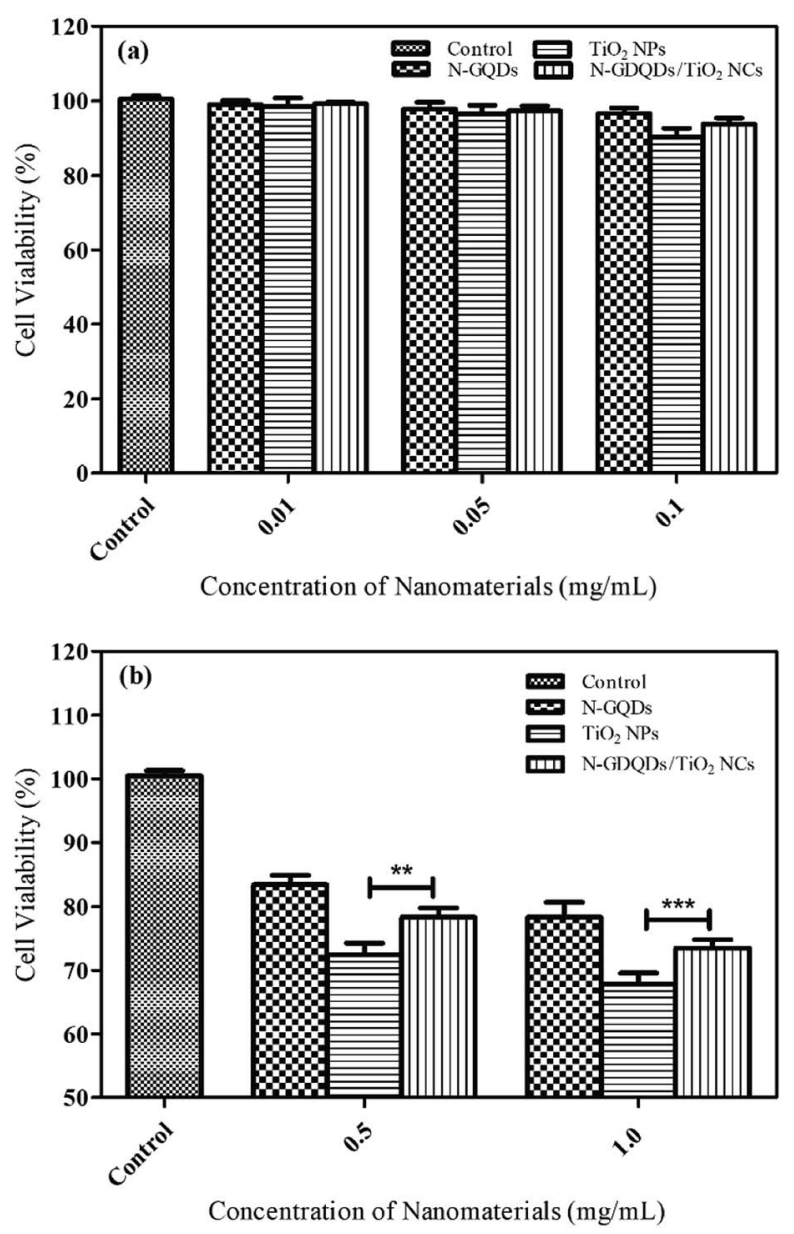

Fig. 10 Cell viability of MDA-MB-231 breast cancer cells post treatment with $\mathrm{N}-\mathrm{GQDs}, \mathrm{TiO}_{2} \mathrm{NPs}$ and $\mathrm{N}-\mathrm{GQDs} / \mathrm{TiO}_{2} \mathrm{NCs}$ (a) low concentration and (b) high concentration. Data represented are mean \pm SD of two identical experiments made in three replicates. Significant difference as compared to $\mathrm{TiO}_{2} \mathrm{NPs} * *(p<0.01)$, ***( $\left.p<0.001\right)$.

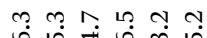

biological effects. ${ }^{64}$ As for crystallinity, due to wider absorption gap and smaller electron effective mass of anatase which results in greater generation of ROS than rutile $\mathrm{TiO}_{2}$. The HRTEM of $\mathrm{TiO}_{2}$ NPs reveals the particles were in nanoscopic scale. Apart from that, metallic components of nanoparticles can cause different effects in human body. For instance, cadmium from cadmium selenide (CdSe) is a toxic metal while titanium is nontoxic and harmless metal. $\mathrm{TiO}_{2}$ NPs are insoluble, resulting in low toxicity as compared with soluble nanoparticles $\left(\mathrm{ZnO}, \mathrm{Fe}_{2} \mathrm{O}_{3}\right.$ and $\left.\mathrm{Ca}_{3}\left(\mathrm{PO}_{4}\right)_{2}\right)$ which are highly toxic. For instance, the toxicity of $\mathrm{ZnO}$ NPs could be related to release of toxic $\mathrm{Zn}^{2+}$ which can cause cell death through breakdown of the mitochondrial membrane potential. ${ }^{65}$

Based on the results in Fig. 10b, N-GQD/TiO ${ }_{2}$ NCs showed small decrease in cell viability except at the highest concentrations $\left(0.5\right.$ and $1.0 \mathrm{mg} \mathrm{mL}^{-1}$ ) tested after $48 \mathrm{~h}$ incubation and thus, inducing low biological effects. The viability trend significantly increased as compared to $\mathrm{TiO}_{2} \mathrm{NPs}$ at $0.5(p<0.01)$ and $1.0 \mathrm{mg} \mathrm{mL}^{-1}(p<0.001)$, since the toxicity level of $\mathrm{TiO}_{2} \mathrm{NPs}$ 
is more prominent as compared with the nanocomposite. This due to the particle size of the $\mathrm{TiO}_{2}$ in the nanocomposite (9.16 \pm $2.4 \mathrm{~nm})$ differs slightly as that of synthesised $\mathrm{TiO}_{2}$ NPs $(11.46 \pm$ $2.8 \mathrm{~nm}$ ), since size of the particle is one of the important parameters in inducing toxicity. ${ }^{66}$ Besides, the good biocompatibility properties of N-GQDs helps to reduce the toxicity of $\mathrm{TiO}_{2}$ NPs. It can be concluded that surface-modification using $\mathrm{N}$-GQDs has no influence on inducing additional toxicity, besides it helps to lower the toxicity effects of $\mathrm{TiO}_{2} \mathrm{NPs}$.

\section{Conclusions}

In this study, N-GQDs and $\mathrm{N}-G Q D s / \mathrm{TiO}_{2}$ NCs have been successfully synthesised through one and two-pot hydrothermal reaction, respectively, while $\mathrm{TiO}_{2}$ NPs was synthesised using microwave-assisted reaction. Based on HRTEM, the average diameter of spherical-shaped N-GQDs was $4.40 \pm 1.5 \mathrm{~nm}$, while $\mathrm{TiO}_{2}$ NPs were irregular square-shaped with $11.46 \pm 2.8 \mathrm{~nm}$ diameter. Upon incorporating N-GQDs into $\mathrm{TiO}_{2} \mathrm{NPs}$, the size of the particles does not differ dramatically $(9.16 \pm 2.4 \mathrm{~nm})$ and the $\mathrm{TiO}_{2}$ NPs were located on the 2D graphene nanosheets surface in a considerably uniform distribution. Based on the result presented, the effect of nanoparticles on MDA-MB-231 cells shows a concentration-dependent decrease, and as the dosage of the nanoparticles increases, the cell viability decreases. Moreover, conjugating N-GQDs reduces the toxicity effect of pristine $\mathrm{TiO}_{2}$ NPs while remaining the size of the particles. This approach addresses the toxicity effect of pristine $\mathrm{TiO}_{2}$ NPs without altering its unique properties by remaining the nano-scale size of the particles.

\section{Conflicts of interest}

There are no conflicts to declare.

\section{Acknowledgements}

This work is financially supported by USM Research University Individual Grant (1001/PKimia/8011086). The corresponding author H. L. Lee would like to acknowledge the Royal Society of Chemistry (RSC) Research Mobility Grant (M19-2989) for her research attachment at University College London, United Kingdom. The authors also wish to thank Dr Vikneswaran Murugaiyah and Mr Khor Boon Keat from School of Pharmaceutical Sciences, USM for their assistance and discussion in this project.

\section{Notes and references}

1 M. Pelaez, N. T. Nolan, S. C. Pillai, M. K. Seery, P. Falaras, A. G. Kontos and D. D. Dionysiou, A review on the visible light active titanium dioxide photocatalysts for environmental applications, Appl. Catal., B, 2012, 125, 331349.

2 I. Ali, M. Suhail, Z. A. Alothman and A. Alwarthan, Recent advances in syntheses, properties and applications of $\mathrm{TiO}_{2}$ nanostructures, RSC Adv., 2018, 8, 30125-30147.
3 V. Vadlapudi and M. Behara, Synthesis of green metallic nanoparticles (NPs) and applications, Orient. J. Chem., 2013, 29, 1589-1595.

4 M. Li, J.-J. Yin, W. G. Wamer and Y. M. Lo, Mechanistic characterization of titanium dioxide nanoparticle-induced toxicity using electron spin resonance, J. Food Drug Anal., 2014, 22, 76-85.

5 D. Kim, M. K. Yu, T. S. Lee, J. J. Park, Y. Y. Jeong and S. Jon, Amphiphilic polymer-coated hybrid nanoparticles as CT/ MRI dual contrast agents, Nanotechnology, 2011, 22, 155101.

6 S. Çeşmeli and C. B. Avci, Application of titanium dioxide $\left(\mathrm{TiO}_{2}\right)$ nanoparticles in cancer therapies, J. Drug Targeting, 2018, 27, 762-766.

7 L. Liu, P. Miao, Y. Xu, Z. Tian, Z. Zou and G. Li, Study of Pt/ $\mathrm{TiO}_{2}$ nanocomposite for cancer-cell treatment, J. Photochem. Photobiol., B, 2010, 98, 207-210.

8 S. J. Klaine, P. J. Alvarez, G. E. Batley, T. F. Fernandes, R. D. Handy, D. Y. Lyon, S. Mahendra, M. J. McLaughlin and J. R. Lead, Nanomaterials in the environment: behavior, fate, bioavailability, and effects, Environ. Toxicol. Chem., 2008, 27, 1825.

9 C. L. Browning, Titanium dioxide nanoparticles are not cytotoxic or clastogenic in human skin cells, J. Environ. Anal. Toxicol., 2014, 4, 239.

10 R. A. Baan, Carcinogenic hazards from inhaled carbon black, titanium dioxide, and talc not containing asbestos or asbestiform fibers: recent evaluations by an IARC Monographs Working Group, Inhalation Toxicol., 2007, 19(supp. 1), 213-228.

11 J. Ahmad, M. Siddiqui, M. Akhtar, H. Alhadlaq, A. Alshamsan, S. Khan, R. Wahab, A. Al-Khadhairy, A. AlSalim, J. Musarrat, Q. Saquib, M. Fareed and M. Ahamed, Copper doping enhanced the oxidative stress-mediated cytotoxicity of $\mathrm{TiO}_{2}$ nanoparticles in A549 cells, Hum. Exp. Toxicol., 2017, 37, 496-507.

12 M. Ahamed, M. A. M. Khan, M. J. Akhtar, H. A. Alhadlaq and A. Alshamsan, Role of $\mathrm{Zn}$ doping in oxidative stress mediated cytotoxicity of $\mathrm{TiO}_{2}$ nanoparticles in human breast cancer MCF-7 cells, Sci. Rep., 2016, 6, 30196.

13 M. Ahamed, M. A. M. Khan, M. J. Akhtar, H. A. Alhadlaq and A. Alshamsan, Ag-doping regulates the cytotoxicity of $\mathrm{TiO}_{2}$ nanoparticles via oxidative stress in human cancer cells, Sci. Rep., 2017, 7, 17662.

14 T. López, M. Alvarez, R. D. González, M. J. Uddin, J. Bustos, S. Arroyo and A. Sánchez, Synthesis, characterization and in vitro cytotoxicity of $\mathrm{Pt}-\mathrm{TiO}_{2}$ nanoparticles, Adsorption, 2011, 17, 573-581.

15 L. Liu, M. Sun, Q. Li, H. Zhang, P. J. Alvarez, H. Liu and W. Chen, Genotoxicity and cytotoxicity of cadmium sulfide nanomaterials to mice: comparison between nanorods and nanodots, Environ. Eng. Sci., 2014, 31, 373-380.

16 W.-H. Chan and N.-H. Shiao, Cytotoxic effect of CdSe quantum dots on mouse embryonic development, Acta Pharmacol. Sin., 2008, 29, 259-266.

17 S. Latvala, J. Hedberg, S. D. Bucchianico, L. Möller, I. O. Wallinder, K. Elihn and H. L. Karlsson, Nickel release, 
ROS generation and toxicity of $\mathrm{Ni}$ and $\mathrm{NiO}$ micro- and nanoparticles, PLoS One, 2016, 11, e0159684.

18 T. Barkhade, S. Mishra, H. Chander, S. K. Mahapatra and I. Banerjee, Effect of $\mathrm{TiO}_{2}$ and $\mathrm{Fe}$ doped $\mathrm{TiO}_{2}$ nanoparticles on mitochondrial membrane potential in HBL-100 cells, Biointerphases, 2019, 14, 041003.

19 X. Hai, J. Feng, X. Chen and J. Wang, Tuning the optical properties of graphene quantum dots for biosensing and bioimaging, J. Mater. Chem. B, 2018, 6, 3219-3234.

20 L.-L. Li, J. Ji, R. Fei, C.-Z. Wang, Q. Lu, J.-R. Zhang, L.-P. Jiang and J.-J. Zhu, A facile microwave avenue to electrochemiluminescent two-color graphene quantum dots, Adv. Funct. Mater., 2012, 22, 2971-2979.

21 T. P. D. Shareena, D. Mcshan, A. K. Dasmahapatra and P. B. Tchounwou, A review on graphene-based nanomaterials in biomedical applications and risks in environment and health, Nano-Micro Lett., 2018, 10, DOI: 10.1007/s40820-018-0206-4.

22 W. A. Saidi, Oxygen reduction electrocatalysis using N-doped graphene quantum-dots, J. Phys. Chem. Lett., 2013, 4, 41604165.

23 Z. Jin, P. Owour, S. Lei and L. Ge, Graphene, graphene quantum dots and their applications in optoelectronics, Curr. Opin. Colloid Interface Sci., 2015, 20, 439-453.

24 F. Lu, Y.-H. Zhou, L.-H. Wu, J. Qian, S. Cao, Y.-F. Deng and Y. Chen, Highly fluorescent nitrogen-doped graphene quantum dots synthesis and their applications as $\mathrm{Fe}(\mathrm{III})$ ions sensor, Int. J. Opt., 2019, 2019, 1-9.

25 V. B. Parambhath, R. Nagar and S. Ramaprabhu, Effect of nitrogen doping on hydrogen storage capacity of palladium decorated graphene, Langmuir, 2012, 28, 78267833.

26 S. Syama and P. V. Mohanan, Comprehensive application of graphene: emphasis on biomedical concerns, Nano-Micro Lett., 2019, 11, DOI: 10.1007/s40820-019-0237-5.

27 A. Karami, Synthesis of $\mathrm{TiO}_{2}$ nano powder by the sol-gel method and its use as a photocatalyst, J. Iran. Chem. Soc., 2010, 7, S154-S160.

28 P. Shinde and C. Bhosale, Properties of chemical vapour deposited nanocrystalline $\mathrm{TiO}_{2}$ thin films and their use in dye-sensitized solar cells, J. Anal. Appl. Pyrolysis, 2008, 82, 83-88.

29 R. K. Wahi, Y. Liu, J. C. Falkner and V. L. Colvin, Solvothermal synthesis and characterization of anatase $\mathrm{TiO}_{2}$ nanocrystals with ultrahigh surface area, J. Colloid Interface Sci., 2006, 302, 530-536.

30 H. Arami, M. Mazloumi, R. Khalifehzadeh and S. Sadrnezhaad, Sonochemical preparation of $\mathrm{TiO}_{2}$ nanoparticles, Mater. Lett., 2007, 61, 4559-4561.

31 M. I. Dar, A. K. Chandiran, M. Grätzel, M. K. Nazeeruddin and S. A. Shivashankar, Controlled synthesis of $\mathrm{TiO}_{2}$ nanoparticles and nanospheres using a microwave assisted approach for their application in dye-sensitized solar cells, J. Mater. Chem. A, 2014, 2, 1662-1667.

32 X. Jia, W. He, X. Zhang, H. Zhao, Z. Li and Y. Feng, Microwave-assisted synthesis of anatase $\mathrm{TiO}_{2}$ nanorods with mesopores, Nanotechnology, 2007, 18, 075602.
33 M. Kaur, M. Kaur and V. K. Sharma, Nitrogen-doped graphene and graphene quantum dots: a reviewon synthesis and applications in energy, sensors and environment, Adv. Colloid Interface Sci., 2018, 259, 44-64.

34 R. Giovannetti, E. Rommozzi, M. Zannotti and C. A. D'Amato, Recent advances in graphene based $\mathrm{TiO}_{2}$ nanocomposites $\left(\mathrm{GTiO}_{2} \mathrm{Ns}\right)$ for photocatalytic degradation of synthetic dyes, Catalysts, 2017, 7, 305.

35 A. B. Ganganboina, A. D. Chowdhury and R.-A. Doong, Nano assembly of $\mathrm{N}$-doped graphene quantum dots anchored $\mathrm{Fe}_{3} \mathrm{O}_{4} /$ halloysite nanotubes for high performance supercapacitor, Electrochim. Acta, 2017, 245, 912-923.

36 T. V. Tam, N. B. Trung, H. R. Kim, J. S. Chung and W. M. Choi, One-pot synthesis of N-doped graphene quantum dots as a fluorescent sensing platform for $\mathrm{Fe}^{3+}$ ions detection, Sens. Actuators, B, 2014, 202, 568-573.

37 H. Yu, Y. Zhao, C. Zhou, L. Shang, Y. Peng, Y. Cao, L.-Z. Wu, C.-H. Tung and T. Zhang, Carbon quantum dots $/ \mathrm{TiO}_{2}$ composites for efficient photocatalytic hydrogen evolution, J. Mater. Chem. A, 2014, 2, 3344.

38 A. Peter, L. Mihaly-Cozmuta, A. Mihaly-Cozmuta, C. Nicula, A. Jastrzębska, P. Kurtycz and A. Olszyna, Morphology, structure, and photoactivity of two types of graphene oxide- $\mathrm{TiO}_{2}$ composites, Chem. Pap., 2015, 69, 839-855.

39 B. K. Vijayan, N. M. Dimitrijevic, D. Finkelstein-Shapiro, J. Wu and K. A. Gray, Coupling titania nanotubes and carbon nanotubes to create photocatalytic nanocomposites, ACS Catal., 2012, 2, 223-229.

40 X. Sun, H.-J. Li, N. Ou, B. Lyu, B. Gui, S. Tian, D. Qian, $\mathrm{X}$. Wang and J. Yang, Visible-light driven $\mathrm{TiO}_{2}$ photocatalyst coated with graphene quantum dots of tunable nitrogen doping, Molecules, 2019, 24, 344.

41 L. Tang, R. Ji, X. Li, G. Bai, C. P. Liu, J. Hao, J. Lin, H. Jiang, K. S. Teng, Z. Yang and S. P. Lau, Deep ultraviolet to nearinfrared emission and photoresponse in layered $\mathrm{N}$ - doped graphene quantum dots, ACS Nano, 2014, 8, 6312-6320.

42 B. Zheng, Y. Chen, P. Li, Z. Wang, B. Cao, F. Qi, J. Liu, Z. Qiu and W. Zhang, Ultrafast ammonia-driven, microwaveassisted synthesis of nitrogen-doped graphene quantum dots and their optical properties, Nanophotonics, 2016, 6, 259-267.

43 I. Medina-Ramírez, J. L. Liu, A. Hernández-Ramírez, C. Romo-Bernal, G. Pedroza-Herrera, J. Jáuregui-Rincón and M. A. Gracia-Pinilla, Synthesis, characterization, photocatalytic evaluation, and toxicity studies of $\mathrm{TiO}_{2}-\mathrm{Fe}^{3+}$ nanocatalyst, J. Mater. Sci., 2014, 49, 5309-5323.

44 L. Chao, Z. Liqiang, R. Liu, G. Zhenfei, Y. Xiaopeng, T. Zhiqiang, Y. Fan, Y. Zhizhen, C. Lishan, X. Chunming and L. Yongfeng, Hydrothermal Synthesis of N-doped $\mathrm{TiO}_{2}$ nanowires and $\mathrm{N}$-doped graphene heterostructures with enhanced photocatalytic properties, J. Alloys Compd., 2015, 656, 24-32.

45 Z. Yang, Z. Li, M. Xu, Y. Ma, J. Zhang, Y. Su, F. Gao, H. Wei and L. Zhang, Controllable synthesis of fluorescent carbon dots and their detection application as nanoprobes, NanoMicro Lett., 2013, 5, 247-259. 
46 X. Wang, J. Tian, C. Fei, L. Lv, Y. Wang and G. Cao, Rapid construction of $\mathrm{TiO}_{2}$ aggregates using microwave assisted synthesis and its application for dye-sensitized solar cells, RSC Adv., 2015, 5, 8622-8629.

47 S. Mahshid, M. Askari and M. S. Ghamsari, Synthesis of $\mathrm{TiO}_{2}$ nanoparticles by hydrolysis and peptization of titanium isopropoxide solution, J. Mater. Process. Technol., 2007, 189, 296-300.

48 S. S. Muniandy, N. H. M. Kaus, Z.-T. Jiang, M. Altarawneh and H. L. Lee, Green synthesis of mesoporous anatase $\mathrm{TiO}_{2}$ nanoparticles and their photocatalytic activities, $R S C$ Adv., 2017, 7, 48083-48094.

49 A. Jena, R. Vinu, S. A. Shivashankar and G. Madras, Microwave assisted synthesis of nanostructured titanium dioxide with high photocatalytic activity, Ind. Eng. Chem. Res., 2010, 49, 9636-9643.

50 C. O. Kappe, A. Stadler, D. Dallinger, R. Mannhold, H. Kubinyi and G. Folkers, Microwaves in Organic and Medicinal Chemistry, second, completely revised and enlarged, Wiley, Weinheim, 2012.

51 Q. Zhang, N. Bao, X. Wang, X. Hu, X. Miao, M. Chaker and D. Ma, Advanced fabrication of chemically bonded graphene/ $/ \mathrm{TiO}_{2}$ continuous fibers with enhanced broadband photocatalytic properties and involved mechanisms exploration, Sci. Rep., 2016, 6, 38066.

52 T. Hanawa, A comprehensive review of techniques for biofunctionalization of titanium, J. Periodontal Implant Sci., 2011, 41, 263.

53 B. Derjaguin and L. Landau, Theory of the stability of strongly charged lyophobic sols and of the adhesion of strongly charged particles in solutions of electrolytes, Prog. Surf. Sci., 1993, 43, 30-59.

54 P. Bihari, M. Vippola, S. Schultes, M. Praetner, A. G. Khandoga, C. A. Reichel, C. Coester, T. Tuomi, M. Rehberg and F. Krombach, Optimized dispersion of nanoparticles for biologcal in vitro and in vivo studies, Part. Fibre Toxicol., 2008, 5, 14.

55 M. I. Setyawati, C. Y. Tay and D. T. Leong, Mechanistic investigation of the biological effects of $\mathrm{SiO}_{2}, \mathrm{TiO}_{2}$, and ZnO nanoparticles on intestinal cells, Small, 2015, 11, 3458-3468.
56 M. Lundqvist, J. Stigler, G. Elia, I. Lynch, T. Cedervall and K. A. Dawson, Nanoparticle size and surface properties determine the protein corona with possible implications for biological impacts, Proc. Natl. Acad. Sci. U. S. A., 2008, 105, 14265-14270.

57 Z. Ji, X. Jin, S. George, T. Xia, H. Meng, X. Wang, E. Suarez, H. Zhang, E. M. V. Hoek, H. Godwin, A. E. Nel and J. I. Zink, Dispersion and stability optimization of $\mathrm{TiO}_{2}$ nanoparticles in cell culture media, Environ. Sci. Technol., 2010, 44, 7309-7314.

58 D. Jiang, Y. Chen, N. Li, W. Li, Z. Wang, J. Zhu and S. Xu, Synthesis of luminescent graphene quantum dots with high quantum yield and their toxicity study, PLoS One, 2015, 10, e0144906.

59 S. Wang, I. S. Cole and Q. Li, The toxicity of graphene quantum dots, RSC Adv. , 2016, 6, 89867-89878.

60 T. Wang, S. Zhu and X. Jiang, Toxicity mechanism of graphene oxide and nitrogen-doped graphene quantum dots in RBCs revealed by surface-enhanced infrared absorption spectroscopy, Toxicol. Res., 2015, 4, 885-894.

61 D. Qu, M. Zheng, J. Li, Z. Xie and Z. Sun, Tailoring color emissions from $\mathrm{N}$-doped graphene quantum dots for bioimaging applications, Light: Sci. Appl., 2015, 4, e364.

62 B. Zhang, P. Wei, Z. Zhou and T. Wei, Interactions of graphene with mammalian cells: molecular mechanisms and biomedical insights, Adv. Drug Delivery Rev., 2016, 105, 145-162.

63 K. Bhattacharya, M. Davoren, J. Boertz, R. P. Schins, E. Hoffmann and E. Dopp, Titanium dioxide nanoparticles induce oxidative stress and DNA-adduct formation but not DNA-breakage in human lung cells, Part. Fibre Toxicol., 2009, 6, 17.

64 D. Warheit, R. Hoke, C. Finlay, E. Donner, K. Reed and C. Sayes, Development of a base set of toxicity tests using ultrafine $\mathrm{TiO}_{2}$ particles as a component of nanoparticle risk management, Toxicol. Lett., 2007, 171, 99-110.

65 A. Nel, Toxic potential of materials at the nanolevel, Science, 2006, 311, 622-627.

66 I. Pujalté, I. Passagne, B. Brouillaud, M. Tréguer, E. Durand, C. Ohayon-Courtès and B. Lazou, Cytotoxicity and oxidative stress induced by different metallic nanoparticles on human kidney cells, Part. Fibre Toxicol., 2011, 8, 10. 